\title{
BMJ Open Physical activities and influencing factors among public health nurses: a cross-sectional study
}

\author{
Miao-Ling Lin, ${ }^{1,2}$ Joh-Jong Huang, ${ }^{3}$ Hung-Yi Chuang, ${ }^{4}$ Hsiu-Min Tsai, ${ }^{5}$ \\ Hsiu-Hung Wang ${ }^{1}$
}

To cite: Lin M-L, Huang J-J, Chuang $\mathrm{H}-\mathrm{Y}$, et al. Physical activities and influencing factors among public health nurses: a cross-sectional study. BMJ Open 2018;8:e019959. doi:10.1136/ bmjopen-2017-019959

- Prepublication history for this paper is available online To view these files, please visit the journal online (http://dx.doi. org/10.1136/bmjopen-2017019959).

Received 7 October 2017 Revised 12 March 2018 Accepted 23 March 2018

Check for updates

${ }^{1}$ College of Nursing, Kaohsiung Medical University, Kaohsiung, Taiwan

${ }^{2}$ Long-Term Care Division, Department of Health, Kaohsiung City Government, Kaohsiung, Taiwan

${ }^{3}$ Graduate Institute of Gender Studies, Kaohsiung Medical University, Kaohsiung, Taiwan ${ }^{4}$ Department of Public Health, Kaohsiung Medical University, Kaohsiung, Taiwan

${ }^{5}$ Department of Nursing, Chang Gung University of Science and Technology, Taoyuan, Taiwan

Correspondence to Professor Hsiu-Hung Wang; hhwang@kmu.edu.tw

\section{ABSTRACT}

Objectives Public health nurses are responsible for promoting and managing the health of community members, and if they do not have enough physical activity or ignore their own health, not only will their own health decline but the quality of life of the public will also be affected. This study investigated the physical activity of public health nurses and analysed the effects of attitudes, subjective norms, perceived behavioural control and behavioural intention to engage in physical activity. Methods This study adopted a cross-sectional research design, and convenience sampling was used to select the research subjects. 198 public health nurses were invited to participate, and 172 completed the questionnaire. Multiple linear regression was used to analyse the influencing factors of physical activity intention and physical activity. Results Attitudes towards physical activity and perceived behavioural control of physical activity affected physical activity intention. When they had higher behavioural intention, their physical activity behaviour also improved. The physical activity intention significantly influenced the number of days that they had engaged in vigorous physical activity $(95 \% \mathrm{Cl} 0.1786$ to $0.3060, \mathrm{p}<0.0001)$, and significantly influenced the number of days that they walked daily for $10 \mathrm{~min}(95 \% \mathrm{Cl} 0.2158$ to 0.4144 , $\mathrm{p}<0.0001)$, and also significantly influenced their daily sedentary time $(95 \% \mathrm{Cl}-0.3020$ to $0.0560, \mathrm{p}=0.0046)$. Conclusions Encouraging public health nurses to heed their own health and motivating them to engage in physical activity warrants attention from policy-makers and government health agencies.

\section{INTRODUCTION}

In 2014, WHO named 'insufficient physical activity' as an issue warranting attention from international public health agencies. Over 14 million individuals die from chronic disease, and one of the primary reasons is physical inactivity. ${ }^{1}$ Research has shown that physical inactivity is a worldwide concern in leading cause of morbidity, disability and premature mortality. ${ }^{2}$ In the past 30 years in the USA, the proportion of individuals who are physically inactive has gradually declined in every state, but the prevailing rate of physical inactivity in many states remains high. ${ }^{3}$ In

\section{Strengths and limitations of this study}

- The health promotion behaviour of public health nurses has rarely been explored; in this study, the theory of planned behaviour was applied to explore the influencing factors of physical activity among public health nurses.

- In this study, the data were objectively collected with various physical activities and the relevant factors.

- This study was limited in terms of analysing some of the confounding factors that may affect physical activity, such as obesity and disability.

- The study adapted cross-sectional design, therefore, the result of the study could not be used as the inference of cause and effect.

- The inference of the results would be limited as the participants were limited to specific targets.

the past, the number of Taiwanese who did not engage in physical activity was 2.5 times that of Americans. In 2012, the Health Promotion Administration of Taiwan conducted a survey of physical activity among Taiwanese people and found that, among those aged 12-64 years, the average proportion of those who had done no physical activity in the last week was $29.4 \%$. The proportion of women who had done no physical activity in the last week $(30.7 \%)$ was higher than that of men $(28.0 \%)$, especially among those aged $42-51$ years. Therefore, the risk of insufficient physical activity for the health of Taiwanese people warrants attention. ${ }^{4}$

In Taiwan, public health centres are the basic agencies promoting public health work. As of the end of 2015, Taiwan has 370 public health centres, which provide community members with basic medical insurance and public health services, and health promotion is one of the essential public health services. ${ }^{5}$ Thus, promoting healthy living and physical activity is an essential activity of public health nurses at public health centres. Empirical evidence has confirmed that RNs' personal health behaviours are related to 
their professional health promotion practices. ${ }^{6-8}$ Previous studies have indicated nurses may translate their personal attitudes, beliefs and behaviours into their professional practices related to health promotion ${ }^{9-11}$; therefore, it is important to explore the influencing factors of physical activity of public health nurses.

In 1985, Ajzen proposed the theory of planned behaviour (TPB), in which an individual decides whether to perform an act based on free will. Once people have more positive attitudes and subjective norms and better perceived behavioural control, they are more likely to change specific behavioural intentions into actual behaviours. ${ }^{12}$ A US study based on TPB to examine the influencing factors of physical activity found that attitudes, subjective norms and perceived behavioural control explained $54.8 \%$ of total variance of intention, and intention explained $13.8 \%$ of total variance of physical activity. ${ }^{13}$ Another study examined the physical activity of middle-aged African-American women $(n=137$; mean age $=49.2 \pm 7.8$ ) and found that attitudes and perceived behavioural control explained $57.4 \%$ of total variance of physical activity. ${ }^{14}$ TPB has also been used to survey physical activity in Korean-Americans ( $\mathrm{n}=198$; mean age $=26.0 \pm 9.16$ ).

If people feel that physical activity is enjoyable and effective and that they can control their own physical activity, then there is more positive physical activity intention, so attitude and perceived behavioural control can serve as important predictors of physical activity intention $\left(\mathrm{R}^{2}=0.31\right)$. Meanwhile, physical activity intention and perceived behavioural control could significantly predict physical activity with the explained variance of $43 \% .{ }^{15}$

A US study (from 1976 to 1998), for nurses aged 30-55 $(\mathrm{n}=71570)$ found that more physical activities could reduce endometrial cancer risk, and make it less likely nurses would smoke, be less likely to have diabetes, higher alcohol and energy intakes but lower caffeine intake, and spend less time sitting. ${ }^{16}$ Health behaviour healthcare providers had a crucial effect on patients and the public; therefore, health behaviour of healthcare providers should be a concern. ${ }^{17}$ Healthcare providers are the gatekeepers of both patient and public health, so they need to pay attention to their own health. In addition, public health nurses are the first-line providers of healthcare to the public and must be even more self-aware of their health to serve as health promotion advocates and role models.

Public health nurses are important promoters of community health, but there have been few studies investigating the health behaviours of public health nurses. Public health nurses are in the front line to serve the public, and if they disregard or ignore their own health, their own health will decline and the quality of life of the public will be affected. To maintain public health, the health of nurses must receive appropriate attention. Thus, the purpose of this study is to investigate the physical activity of public health nurses and analyse the influence of attitudes, subjective norms, perceived behavioural control and behavioural intention to engage in physical activity. The results of this study are expected to support increased physical activity among public health nurses and serve as an important reference for policy-making.

\section{METHODS}

\section{Study design}

This is a cross-sectional and correlational study with a questionnaire survey.

\section{Participants}

Participants' inclusion criteria of this study: (1) public health nurses serving at a Kaohsiung City public health centre and (2) willingness to participate in the study. Exclusion criteria: (1) currently pregnant and (2) have a health problem that makes physical activity unsuitable.

\section{Recruitment}

Participants were recruited from 38 district public health centres of Kaohsiung in Taiwan. Before the study, participants were informed about the purpose of the study and consent was obtained. The questionnaire was collected from January 2016 to February 2016. Altogether, 226 Kaohsiung public health nurses were invited to participate in the study through email. In total, 198 public health nurses were enrolled, and 172 completed the questionnaire, with a response rate of $86.9 \%$.

\section{Data collection tool}

This study used TPB as a theory and referenced research tools used in previous studies of physical activity ${ }^{14} 18$ to develop questionnaires for public health nurses, including Demographic Inventory, Attitudes towards Physical Activity Scale (APAS), Subjective Norms of Physical Activity Scale (SNPAS), Perceived Behavioural Control of Physical Activity Scale (PBCPAS) and Physical Activity Intention Scale (PAIS). The content validity was evaluated by medical, sports, nursing and public health professionals, and obtained content validity index of 0.88 . In a pilot study of public health nurses ( $n=30)$, Cronbach's alpha of the internal consistency as well as 1-week testretest reliability of the questionnaire was examined. The Taiwan Version of International Physical Activity Questionnaire (TV-IPAQ), authorised for use by the Taiwan Ministry of Health, served as a tool for measuring physical activity.

\section{Demographic inventory}

The Demographic inventory includes age, educational level, marital status, work experience, public health work qualification, number of children and disease condition.

\section{Attitudes towards Physical Activity Scale}

The APAS includes nine items to measure subjective attitude towards physical activity, for example: 'for me, exercise is a healthy thing' and 'for me, sports are worth doing.' Each item comprises a Likert's scale ranging from 1 to 5 . A total score for the Scale ranges from 9 to 45 . The 
higher score indicates higher level of attitude towards physical activity. The Cronbach's alpha and 1-week testretest reliability coefficients are 0.81 and 0.91 , respectively, in the pilot study. The Cronbach's alpha is 0.84 in the present study.

\section{Subjective Norms of Physical Activity Scale}

The SNPAS includes six items to measure friends, surrounding support systems and the effects of the environment on physical activity, such as 'my friends or family think I should exercise' and 'my environment makes it easy to go somewhere to exercise.' Each item comprises a Likert's scale ranging from 1 to 5 . A total score ranges from 6 to 30. The higher score indicates higher level of positive subjective norms of physical activity. The Cronbach's alpha and 1 week test-retest reliability coefficients are 0.82 and 0.89 , respectively, in the pilot study. The Cronbach's alpha is 0.80 in the present study.

\section{Perceived Behavioural Control of Physical Activity Scale}

The PBCPAS includes seven items to measure difficulty of engaging in physical activity, subjective control and other feelings, such as 'I have time for exercise' and 'I can decide on my own whether to exercise.' Each item comprises a Likert's scale ranging from 1 to 5 . A total score ranges from 7 to 35 . The higher score indicates higher level of perceived behavioural control. The Cronbach's alpha and 1-week test-retest reliability coefficients are 0.72 and 0.88 , respectively, in the pilot study. The Cronbach's alpha is 0.75 in the present study.

\section{Physical Activity Intention Scale}

The PAIS includes four items to measure physical activity and the likelihood of and motivation physical activity in the coming week, such as 'I want to start (or continue) exercising next week' and 'I will try to exercise starting (or continuing) next week.' Each item comprises a Likert's scale ranging from 1 to 5 . A total score ranges from 4 to 20. The higher score indicates higher level of behavioural intention. The Cronbach's alpha and 1-week test-retest reliability coefficients are 0.93 and 0.92 , respectively, in the pilot study. The Cronbach's alpha is 0.95 in the present study.

\section{TV-IPAQ (short version)}

The TV-IPAQ (short version (SS)) was used to measure physical activity. The content validity was 0.994 and 0.992 for language equivalence and meaning similarity between the English and Taiwan versions of the IPAQ-SS, and consistency values for the English and Chinese versions in terms of intraclass correlation coefficients was $0.704 .{ }^{14}$ The TV-IPAQ (SS) primarily measures the physical activity of the participants in the past 7 days, including vigorous physical activity, moderately vigorous physical activity, daily walk time and daily sedentary time.

\section{Ethical considerations}

Data were collected from January 2016 to February 2016. The study was conducted by the principal investigator contacting the in-charge nurse at each district's public health centre via phone or mail to invite public health nurses to participate in a questionnaire survey. Before data collection began, the study participants acknowledged the purpose and process of the study and the maintenance of their rights and signed a consent form. The study participants voluntarily completed the questionnaires and could consult with the researcher at any time if there were any questions during the process. After completing the questionnaire, the study participants returned the questionnaires to the in-charge nurse or sent them directly by mail to the principal investigator.

\section{Sample size calculation}

Sample size calculation was using G-power 3.1.9.2 software, a general medium effect size of 0.25 was predicted, $\alpha$ was set to 0.05 , power was set to 0.80 and the required sample size was 128 . Besides, extra $30 \%$ of the sample was required in case of missing answers, so at least 196 women were required in total.

\section{Statistical analysis}

Data analyses were performed by using SPSS V.20.0. Descriptive statistics were used to describe the demographic characteristics of the participants and the scales' scores. Pearson's correlation was used to examine the relationship among the variables. Multiple linear regression was used to analyse the influencing factors of physical activity intention and physical activity. In all tests of this study, $p$ value $<0.05$ was set to be statistically significant.

\section{Patient and public involvement}

Through literature review and clinical observation, we proposed the research questions, developed the research instruments and explored public health nurses' physical activity. During the study, the research team recruited public health nurses to participate in the study through the principles of disclosure and informed consent. None of the participants helped recruit and conduct the research. After the study, the research results will be shared with policy-makers to help promote the physical wellness of public health nurses. The findings will also be shared with the participants as a guide to improve their physical activity and health behaviour.

\section{RESULTS}

A total of 172 public health nurses met the inclusion criteria and completed the questionnaires. Nurses were recruited from 38 public health centres in Kaohsiung City. All participants were female, had no disability and their mean body mass index was $23.53 \pm 4.27$. All of them had medical insurance. The mean age of the nurses was $42.98 \pm 6.99$ years. Among them, 167 (97.09\%) had a college or above educational level; 125 (72.67\%) were married. The mean year of work experience was $19.25 \pm 7.00$ years and the year of public health work qualifications was $9.80 \pm 7.58$ years. The mean score on APAS was 
$35.60( \pm 4.64)$ with the actual score range being $20-45$; the mean score on SNPAS was $22.55( \pm 3.40)$ with the actual score range being 14-30; the mean score on PBCPAS was $26.22( \pm 3.60)$ and the actual score range being $14-35$; and the mean score on PAIS was $13.81( \pm 3.30)$ with the actual score range being 4-20.

When comparing the physical activity in the past 7 days and the past 3 months, the majority $(n=103,60.47 \%)$ felt that they were similar. Sixty-eight respondents (39.54\%) had engaged in vigorous physical activity in the past 7 days with an average of 0.97 days $(\mathrm{SD}=1.60)$ of vigorous physical activity per week; 85 respondents (49.42\%) had engaged in moderately vigorous physical activity in the past 7 days, with an average of 1.43 days $(\mathrm{SD}=2.06)$ of moderately vigorous physical activity per week; 123 respondents $(71.51 \%)$ took a daily walk for $10 \mathrm{~min}$, with an average of 2.49 days $(\mathrm{SD}=2.40)$ per week. The average daily sedentary time of the respondents were 8.05 hours in the past 7 days $(\mathrm{SD}=2.74$ ) (table 1 ).

The APAS and SNPAS were significantly correlated $(p=0.0014)$. PBCPAS was also significantly correlated with APAS $(p<0.0001)$ and SNPAS $(p<0.0001)$. APAS, SNPAS and PBCPAS were all significantly correlated with PAIS $(\mathrm{p}<0.0001)$. Multiple regression analysis was used to explore factors predicting physical activity intention. The $p$ value was set as the selection criterion in the selection strategy and key variables were chosen accordingly. After regression diagnosis, key variables influencing public health nurse's physical activity intention were selected from the analytical results, and are presented in table 2. The APAS and PAIS were significantly correlated $(95 \% \mathrm{CI}$ 0.0525 to $0.2499, \mathrm{p}=0.0029$ ). For every point increase in attitude towards physical activity, there was a 0.15 -point increase in physical activity intention. The PBCPAS were also significantly correlated with PAIS (95\% CI 0.2771 to $0.5318, \mathrm{p}<0.0001)$. For every point increase in perceived behavioural control of physical activity, there was a $0.40-$ point increase in physical activity intention.

Multiple regression analysis was also used to explore factors predicting physical activity. The $p$ value was set as the selection criterion in the selection strategy and key variables were chosen accordingly. After regression diagnosis, key variables influencing physical activity behaviour were selected from the analytical results, and are presented in tables 3-5. The physical activity intention significantly influenced the number of days in the past 7 days that they had engaged in vigorous physical activity (95\% CI 0.1786 to $0.3060, \mathrm{p}<0.0001)$. For every point increase in physical activity intention, there was a 0.24 day increase in the time of vigorous physical activity. The physical activity intention also significantly influenced the number of days in the past 7 days that they daily walked for $10 \mathrm{~min}(95 \%$ CI 0.2158 to $0.4144, \mathrm{p}<0.0001)$. For every point increase in physical activity intention, there was a 0.32-day increase in the number of days that respondents took a daily walk for $10 \mathrm{~min}$. The physical activity intention also significantly influenced their daily sedentary time $(95 \% \mathrm{CI}-0.3020$ to $0.0560, \mathrm{p}=0.0046)$. For every

\begin{tabular}{|c|c|c|}
\hline Item & $\mathbf{n}$ & $\%$ \\
\hline \multicolumn{3}{|c|}{$\begin{array}{l}\text { Compare the amount of physical activity in the past } 7 \text { days } \\
\text { and the past } 3 \text { months }\end{array}$} \\
\hline Become more & 26 & 15.12 \\
\hline Become less & 42 & 24.42 \\
\hline About the same & 104 & 60.47 \\
\hline \multicolumn{3}{|l|}{ Vigorous physical activity in the past 7 days } \\
\hline No & 104 & 60.47 \\
\hline Yes & 68 & 39.54 \\
\hline \multicolumn{3}{|l|}{ Daily vigorous physical activity time } \\
\hline None & 105 & 61.05 \\
\hline Under $30 \mathrm{~min}$ & 21 & 12.21 \\
\hline $30 \mathrm{~min}$ or more & 23 & 13.37 \\
\hline Uncertain & 23 & 13.37 \\
\hline \multicolumn{3}{|c|}{ Moderate vigorous physical activity in the past 7 days } \\
\hline No & 87 & 50.58 \\
\hline Yes & 85 & 49.42 \\
\hline \multicolumn{3}{|c|}{ Daily moderate vigorous physical activity time } \\
\hline None & 89 & 51.74 \\
\hline Under $30 \mathrm{~min}$ & 26 & 15.12 \\
\hline $30 \mathrm{~min}$ or more & 31 & 18.02 \\
\hline Uncertain & 26 & 15.12 \\
\hline \multicolumn{3}{|l|}{ Daily walk for $10 \mathrm{~min}$ in the past 7 days } \\
\hline No & 49 & 28.49 \\
\hline \multirow[t]{2}{*}{ Yes } & 123 & 71.51 \\
\hline & Mean & SD \\
\hline $\begin{array}{l}\text { The no of days spent on vigorous } \\
\text { physical activity in the past } 7 \text { days }\end{array}$ & 0.97 & 1.60 \\
\hline $\begin{array}{l}\text { The no of days spent on moderate } \\
\text { vigorous physical activity in the past } \\
7 \text { days }\end{array}$ & 1.43 & 2.06 \\
\hline $\begin{array}{l}\text { The past } 7 \text { days the no of days can be a } \\
\text { daily walk for } 10 \mathrm{~min}\end{array}$ & 2.49 & 2.40 \\
\hline $\begin{array}{l}\text { The average daily sedentary time in the } \\
\text { past } 7 \text { days }\end{array}$ & 8.05 & 2.74 \\
\hline
\end{tabular}

point increase in physical activity intention, there was a 0.18 -hour decrease in daily sedentary time.

\section{DISCUSSION}

In this study, the outcome data may have been clustered by Centre, so the intracluster correlation coefficient was calculated based on the research report of Killip et al. ${ }^{19}$ After calculation, the intracluster correlation coefficients varied between 0.18 and 0.24 . These are significant and translate into a design effect between 1.64 and 1.85 which will mean that some of the more marginally significant findings may not be significant. 
Table 2 Multiple regression analyses for predictive factors of physical activity intention $(n=172)$

\begin{tabular}{|c|c|c|c|c|c|}
\hline Variables & Coefficient & SE & $\mathbf{t}$ & P values & $95 \% \mathrm{Cl}$ \\
\hline Intercept & 13.63 & 0.21 & 64.87 & $<0.0001^{\star}$ & 13.21 to 14.04 \\
\hline APAS & 0.15 & 0.05 & 3.03 & $0.0029^{\star}$ & 0.05 to 0.25 \\
\hline
\end{tabular}

*Adjusted $\mathrm{R}^{2}=0.322$.

APAS, Attitudes towards Physical Activity Scale; PBCPAS, Perceived Behavioural Control of Physical Activity Scale.

According to a 2014 survey by the US Centers for Disease Control, adults without regular physical activity have a higher risk of early death and heart disease, stroke, type 2 diabetes, depression and cancer. ${ }^{1}$ A previous study noted $48.6 \%$ of RNs reported they did not participate in any $30 \mathrm{~min}$ physical activity for most of the week, mainly due to lack of time and motivation, fatigue and $\operatorname{cost}^{20}{ }^{20} \mathrm{~A}$ study focusing on nurses showed that $46.3 \%$ of nurses did not engage in regular physical activity, and lack of regular physical activity was a factor affecting sleep disorders. ${ }^{21}$ In addition, a significant factor correlated with nurse job strain is lack of physical activity. ${ }^{22}$ WHO (2010) recommends that adults over the age of 18 should undertake at least $150 \mathrm{~min}$ of moderate physical activity or $90 \mathrm{~min}$ of vigorous physical activity per week. ${ }^{5}$ The results of this study showed that most public health nurses undertake less than $30 \mathrm{~min}$ of vigorous or moderately vigorous physical activity per week. With reference to past research findings, the results of this study show that Taiwan's public health nurses are leaving themselves at health risk.

Most evidence indicates that professionals' physical activity habits are associated with higher physical activity promoting practices and their counselling practices. ${ }^{11}{ }^{23-25}$ In addition, medical providers and community health workers who have not adopted healthy living or physical activity are less likely to encourage patients or community members to engage in healthy activities. ${ }^{10}$ Taiwan public health nurses are important personnel in advocating physical activity, but they do not practise such health behaviours themselves; therefore, helping public health nurses develop the ability to formulate their own physical activity plans benefits their health and allow them to have more positive attitudes for guiding patients and community members to attain healthy living.

The results of the present study showed that the physical activity intention of public health nurses was affected by attitudes towards physical activity and perceived behavioural control. In addition, physical activity intention also affected the time of vigorous physical activity per

$\begin{aligned} & \text { Table } 3 \\
& \text { of vigorous physical activity }(\mathrm{n}=172)\end{aligned}$
\begin{tabular}{llllll} 
Variables & Coefficient & SE & $\mathbf{t}$ & P values & $95 \%$ Cl \\
\hline Intercept & 0.77 & 0.11 & 7.04 & $<0.0001^{*}$ & 0.55 to 0.98 \\
PAIS & 0.24 & 0.03 & 7.51 & $<0.0001^{*}$ & 0.18 to 0.31
\end{tabular}

${ }^{*}$ Adjusted $R^{2}=0.245$.

PAIS, Physical Activity Intention scale. day, the day of daily walking for 10 min per week and the amount of seated sedentary time per day. Previous studies found the fact that health workers have more physical activity and more positive attitudes about physical activity may make them promote more physical activity to patients. ${ }^{26}{ }^{27}$ Leading public health nurses to pose positive attitudes towards physical activity is an important goal. Despite the fact that their job is to help people increase physical activity, they also need professionals' assistance in planning physical activity programmes. Previous study indicated that nurses take responsibility for the role of health promotion in the practice environment. ${ }^{23}$ They may be able to make huge changes in the health of other people. Therefore, nurses, community health workers and other healthcare providers need to obtain even more health information for guidance in physical activity. ${ }^{28}$ Thus, helping public health nurses develop positive attitudes towards physical activity and allowing them to formulate their own plans for physical activity increases their physical activity intention, thereby enhancing physical activity behaviour.

Walking is the most common form of physical activity among Taiwanese, and $42.6 \%$ of Taiwanese have walking habits. ${ }^{29}$ In the present study, the proportion of public health nurses who engaged in daily walking for $10 \mathrm{~min}$ was also higher than the proportion engaging in vigorous or moderately vigorous physical activity, showing that walking is a common form of physical activity among public health nurses. In a study focusing on walking behaviours among university students, attitude, self-regulation and behavioural intention affected their walking behaviours. ${ }^{30}$

In the present study, the physical activity intention of public health nurses also affected the number of days with daily walk for $10 \mathrm{~min}$. Walking can alleviate lower back pain $^{31}$ and can benefit public health nurses with high workload and work-related stress, helping them understand and appreciate the benefits of walking and stimulating their behavioural intention to take up walking. This

Table 4 Multiple regression analyses for predictive factors of a daily walk for $10 \mathrm{~min}(n=172)$

\begin{tabular}{llllll}
\hline Variables & Coefficient & SE & \multicolumn{1}{l}{ t } & P values & $\mathbf{9 5 \%} \mathbf{C l}$ \\
\hline Intercept & 2.24 & 0.17 & 13.14 & $<0.0001^{*}$ & 1.90 to 2.58 \\
PAIS & 0.32 & 0.05 & 6.26 & $<0.0001^{*}$ & 0.22 to 0.41 \\
\hline
\end{tabular}

${ }^{*}$ Adjusted $\mathrm{R}^{2}=0.183$.

PAIS, Physical Activity Intention Scale. 
Table 5 Multiple regression analyses for predictive factors of the average daily sedentary time $(n=172)$

\begin{tabular}{lccccc}
\hline Variables & Coefficient & SE & t & P values & 95\% Cl \\
\hline Intercept & 8.20 & 0.21 & 38.83 & $<0.0001^{*}$ & 7.78 to 8.61 \\
PAIS & -0.18 & 0.06 & -2.87 & $0.0046^{\star}$ & -0.30 to -0.06 \\
\hline
\end{tabular}

${ }^{*}$ Adjusted $\mathrm{R}^{2}=0.046$.

PAIS, Physical Activity Intention Scale.

allows them to elevate their walking behaviour to an even more beneficial healthy walking, which is a strategy worth consideration.

Long periods of sitting increase the risk of lower back pain, ${ }^{32}$ and extended periods of sitting and watching television is a lifestyle that increases the chance of colon cancer in women. ${ }^{33}$ Studies have shown that reducing sedentary time by $30 \mathrm{~min}$ per day and engaging in at least $10 \mathrm{~min}$ of vigorous or moderately vigorous physical activity has significant benefits for body weight control and preventing metabolic syndrome. ${ }^{34}$ The present study found that public health nurses remained seated without movement for over 8 hours per day. Studies have shown that nurses have sedentary lifestyles, and, although they have relevant health knowledge, they often do not apply their health knowledge to themselves, causing themselves to become a high-risk group for cardiovascular disease. ${ }^{35}$ Therefore, helping public health nurses achieve appropriate physical activity to decrease fatigue and stress and reducing their sedentary lifestyle benefits their health promotion.

According to this study, the physical activity of public health nurses in Taiwan was insufficient. Enhancing their positive attitudes towards physical activity and control of physical activity can both enhance their intention of physical activity, and thus increase the possibility of undertaking physical activity. Public health nurses help people understand the benefits of physical activity, but they also need more workplace resources to support their own physical activity. Therefore, to support public health nurses in their own physical activity by providing courses or programmes they would like or can easily adopt is suggested to the policy-makers in Taiwan government. The public health nurses in Kaohsiung City are the object of this study. Although it already covered more than $70 \%$ of them, the results of the study still have some limitations on the corollary of all public health nurses. Especially many of the confounding factors that affect physical activity do not appear in the study subjects. Therefore, there is a limitation in the research corollary.

\section{CONCLUSIONS}

Public health nurses are responsible for promoting and managing the health of community members, but it is easy for them to ignore their own health promotion. Their attitudes towards physical activity and perceived behavioural control affect their behavioural intention of physical activity. When they have higher behavioural intention, their physical activity behaviour also improves. Therefore, encouraging public health nurses to face their own health situation, helping them develop plans for physical activity and encouraging them to develop motivations for physical activity are issues that should be faced by policy-makers and health agencies.

Acknowledgements The authors thank all participants for their participation and nurse managers of these public health centres for their administrative help.

Contributors M-LL and H-HW made primary contributions to the design, conduct, analysis and interpretation of the research. J-JH and $\mathrm{H}-\mathrm{YC}$ contributed to the study design, data analysis plan and interpretation of the results. H-MT and H-HW contributed to the conduct of the research and interpretation of the results. All authors reviewed the manuscript and had full access to all data in the study and take responsibility for the integrity of the data.

Funding This study was funded by the Ministry of Science and Technology, Taiwan (MOST 104-2314-B-037 -045 -MY3).

Competing interests None declared.

Patient consent Obtained.

Ethics approval Kaohsiung Municipal Kai-Syuan Psychiartic Hospital Institutional Review Board (IRB No KSPH-2015-26).

Provenance and peer review Not commissioned; externally peer reviewed.

Data sharing statement № additional data are available.

Open Access This is an Open Access article distributed in accordance with the Creative Commons Attribution Non Commercial (CC BY-NC 4.0) license, which permits others to distribute, remix, adapt, build upon this work non-commercially, and license their derivative works on different terms, provided the original work is properly cited and the use is non-commercial. See: http://creativecommons.org/ licenses/by-nc/4.0/

(C) Article author(s) (or their employer(s) unless otherwise stated in the text of the article) 2018. All rights reserved. No commercial use is permitted unless otherwise expressly granted.

\section{REFERENCES}

1. World Health Organization (WHO). The world's most common diseases. 2015 http://www.who.int/nmh/publications/ncdinfographic-2014.pdf (accessed 10 Dec 2015).

2. Albright $\mathrm{C}$, Thompson $\mathrm{DL}$. The effectiveness of walking in preventing cardiovascular disease in women: a review of the current literature. $J$ Womens Health 2006;15:271-80.

3. An R, Xiang X, Yang Y, et al. Mapping the prevalence of physical inactivity in U.S. States, 1984-2015. PLoS One 2016;11:1-19.

4. Health Promotion Administration, Ministry of Health and Welfare, Taiwan. National Health Survey, 2012. 2012. http://www.hpa.gov. tw/BHPNet/Web/Stat/StatisticsShow.aspx?No=201403250003t (accessed 20 Dec 2016).

5. Health Promotion Administration, Ministry of Health and Welfare, Taiwan. Annual Report, 2016. 2016. https://www.hpa.gov.tw/Pages/ List. aspx?nodeid=1249 (accessed 20 Jun 2017).

6. Zhang J, While AE, Norman IJ. Knowledge and attitudes regarding influenza vaccination among nurses: a research review. Vaccine 2010;28:7207-14.

7. Zhu DQ, Norman IJ, While AE. The relationship between doctors' and nurses' own weight status and their weight management practices: a systematic review. Obes Rev 2011;12:459-69. 
8. Bakhshi S, While AE. Health professionals' alcohol-related professional practices and the relationship between their personal alcohol attitudes and behavior and professional practices: a systematic review. Int J Environ Res Public Health 2013;11:218-48

9. McDowell N, McKenna J, Naylor PJ. Factors that influence practice nurses to promote physical activity. Br J Sports Med 1997;31:308-13.

10. Esposito EM, Fitzpatrick JJ. Registered nurses' beliefs of the benefits of exercise, their exercise behaviour and their patient teaching regarding exercise. Int J Nurs Pract 2011;17:351-6.

11. Hébert ET, Caughy MO, Shuval K. Primary care providers perceptions of physical activity counselling in a clinical setting: a systematic review. Br J Sports Med 2012;46:625-31.

12. Ajzen I. The theory of planned behavior. Organizational Behavior and Human Decision Processes. 1991;50(2):179-211.

13. Gwin S, Taylor EL, Branscum P, et al. Assessment of factors that predict physical activity among Oklahoma clergy: a theory of planned behavior approach. Fam Community Health 2013;36:193-203.

14. Carter-Parker K, Edwards KA, McCleary-Jones V. Correlates of physical activity and the theory of planned behavior between African American women who are physically active and those who are not. Abnf J 2012;23:51-8.

15. Lee $\mathrm{H}$. The role of descriptive norm within the theory of planned behavior in predicting Korean Americans' exercise behavior. Psychol Rep 2011;109:208-18.

16. Du M, Kraft P, Eliassen $\mathrm{AH}$, et al. Physical activity and risk of endometrial adenocarcinoma in the Nurses' Health Study. Int J Cancer 2014;134:2707-16.

17. Lee $\mathrm{F}-\mathrm{H}$, Li C-Y, Wang $\mathrm{H}-\mathrm{H}$, et al. The utilization of Pap tests among different female medical personnel: A nationwide study in Taiwan. Prev Med 2013;56:406-9.

18. Sun $X Y$, Guo Y, Sun J. [Validation of the integration of health belief model and planned behavior theory]. Beijing Da Xue Xue Bao Yi Xue Ban 2009:41:129-34.

19. Killip S, Mahfoud Z, Pearce K. What is an intracluster correlation coefficient? Crucial concepts for primary care researchers. Ann Fam Med 2004;2:204-8.

20. Malik S, Blake H, Batt M. How healthy are our nurses? New and registered nurses compared. Br J Nurs 2011:20:489-96.

21. Han Y, Yuan Y, Zhang L, et al. Sleep disorder status of nurses in general hospitals and its influencing factors. Psychiatr Danub 2016;28:176-83.
22. Chou LP, Tsai CC, Li CY, et al. Prevalence of cardiovascular health and its relationship with job strain: a cross-sectional study in Taiwanese medical employees. BMJ Open 2016;6:1-9.

23. Fie S, Norman IJ, While AE. The relationship between physicians' and nurses' personal physical activity habits and their healthpromotion practice: a systematic review. Health Educ $J$ 2013;72:102-19.

24. Frank E, Rothenberg R, Lewis $\mathrm{C}$, et al. Correlates of physicians' prevention-related practices. Findings from the Women Physicians' Health Study. Arch Fam Med 2000;9:359-67.

25. Abramson S, Stein J, Schaufele M, et al. Personal exercise habits and counseling practices of primary care physicians: a national survey. Clin J Sport Med 2000;10:40-8.

26. Hidalgo KD, Mielke GI, Parra DC, et al. Health promoting practices and personal lifestyle behaviors of Brazilian health professionals. BMC Public Health 2016;16:1114.

27. Steptoe A, Doherty S, Rink E, et al. Behavioural counselling in general practice for the promotion of healthy behaviour among adults at increased risk of coronary heart disease: randomised trial. BMJ 1999;319:943-7.

28. Burdick L, Mielke GI, Parra DC, et al. Physicians', nurses' and community health workers' knowledge about physical activity in Brazil: A cross-sectional study. Prev Med Rep 2015;2:467-72.

29. Sport Administration, Ministry of Education, Taiwan. 102 years of sports city survey. 2015. http://www.sa.gov.tw/wSite/ct?xltem= 23278\&ctNode=1139\&mp=11 (accessed 16 Jun 2016).

30. Sun G, Acheampong RA, Lin H, et al. Understanding walking behavior among university students using theory of planned behavior. Int J Environ Res Public Health 2015;12:13794-806.

31. Revord LP, Lomond KV, Loubert PV, et al. Acute effects of walking with Nordic poles in persons with mild to moderate low-back pain. Int J Exerc Sci 2016:9:507-13.

32. Alhalabi MS, Alhaleeb H, Madani S. Risk factors associated with chronic low back pain in Syria. Avicenna J Med 2015;5:110-6.

33. Keum N, Cao Y, Oh H, et al. Sedentary behaviors and lightintensity activities in relation to colorectal cancer risk. Int $\mathrm{J}$ Cancer 2016;138:2109-17.

34. Jefferis BJ, Parsons TJ, Sartini C, et al. Does duration of physical activity bouts matter for adiposity and metabolic syndrome? A cross-sectional study of older British men. Int J Behav Nutr Phys Act 2016;13:36

35. Hegde SK, Vijayakrishnan G, Sasankh AK, et al. Lifestyle-associated risk for cardiovascular diseases among doctors and nurses working in a medical college hospital in Tamil Nadu, India. J Family Med Prim Care 2016;5:281-5. 